\title{
Plant based Indigenous Dietary Calcium supplementation on Bone turnover markers among Peri and Postmenopausal women: A Randomised Controlled Trial
}

G. Gayathri ${ }^{1}$, AJ Hemamalini²

${ }^{1}$ Department of Clinical Nutrition, Allied Health Sciences, Sri Ramachandra Institute of Higher Education and Research (DU), Porur, Chennai-600116; ${ }^{2}$ Department of Clinical Nutrition, Allied Health Sciences, Sri Ramachandra Institute of Higher Education and Research (DU), Porur, Chennai-600116

\begin{tabular}{l|l|l|l|l|l|l|l|}
\hline Abstract & Introduction & Methodology & Results & Conclusion & References & Citation & Tables/ Figures \\
\hline
\end{tabular}

Dr. G.Gayathri, Senior lecturer, Department of Clinical Nutrition, Allied Health Sciences, Sri

Ramachandra Institute Of Higher Education And Research (DU), Porur, Chennai-600116

E Mail ID: gayathri.g@sriramachandra.edu.in

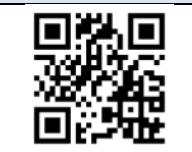

\section{Citation}

Gayathri G, Hemamalini AJ. Plant based Indigenous Dietary Calcium supplementation on Bone turnover markers among Peri and Postmenopausal women: A Randomised Controlled Trial. Indian J Comm Health. 2020;32(4):705-712. https://doi.org/10.47203/IJCH.2020.v32i04.016

Source of Funding: Nil Conflict of Interest: None declared

\section{Article Cycle}

Received: 10/11/2020; Revision: 29/11/2020; Accepted: 17/12/2020; Published: 31/12/2020

This work is licensed under a Creative Commons Attribution 4.0 International License.

\section{Abstract}

Background: Indigenous plant based dietary supplement that is accessible and safer may help to combat the more proclaimed calcium deficiency among Indian population and improve bone strength. Aim \& Objective: To formulate an indigenous calcium rich food supplement and study its impact on markers of bone resorption and formation. Settings and Design: Sixty subjects (80\% power, $\alpha=0.05)$ including 30 perimenopausal and postmenopausal women each were randomly assigned to control and experimental groups. Methods and Material: Experimental postmenopausal and perimenopausal women received $1200 \mathrm{mg}$ and $800 \mathrm{mg}$ per day of calcium respectively from a plant based supplement comprising Sesamum indicum, Eleusine coracana, Glycine max Vigna mungo and Sesbania grandiflora as a midmorning and evening snack. Measures like serum calcium, betacrosslaps (bone resorption marker), total P1NP (bone formation marker) were assessed at baseline, 3rd and 6th month. Results: Fifty-seven subjects were analysed with no adverse events were reported. Results showed that after supplementation betacrosslaps reduced from $0.32 \pm 0.130 \mathrm{ng} / \mathrm{ml}$ to $0.25 \pm 0.130 \mathrm{ng} / \mathrm{ml}$ and $1.11 \pm 0.290$ $\mathrm{ng} / \mathrm{ml}$ to $0.42 \pm 0.263 \mathrm{ng} / \mathrm{ml}$ in perimenopausal and postmenopausal subjects significant at $(\mathrm{P}=0.008)$ and $(\mathrm{P}=0.012)$ respectively. Conclusions: Adequate dietary calcium intake using locally available foods is recommended as a strategic option in reducing risk of osteoporosis.

\section{Keywords}

Dietary calcium, Bone turnover, Betacrosslaps

\section{Introduction}

A natural decline in endogenous estrogen synthesis during menopause reduces bone mineral density (BMD) and incurs negative changes to bone microarchitecture, increasing the risk of osteoporosis and, as a consequence, fracture risk in women.(1) Considering the deliterious effects of pharmacological approach(2), optimizing the consumption of bone-sparing nutrients especially calcium exerts positive impact on skeletal health throughout life by well-characterized physiologic mechanisms.(3) 
Many countries in Asia have average dietary calcium intake less than $500 \mathrm{mg} /$ day and average calcium intake is generally lower in women than men.(4) Aptel, Cance-Rouzaud and Grandjean(5) reported that $100 \mathrm{mg} /$ day increase in dietary calcium and drinking water each was associated with $0.2 \%$ and $0.5 \%$ higher femoral neck BMD, respectively. Good sources of naturally occurring plant calcium are available from food sources such as green leafy vegetables like Agathi (Sesbania grandiflora), sprouted legumes like soyabean (Glycine max) and black gram dal (Vigna mungo), cereals like finger millet (Eleusine coracana), oilseeds like Sesame seeds (Sesamum indicum).

A lacuna in Randomized controlled trials on assessing the efficacy of a natural calcium supplementation from non-dairy sources was identified through an extensive review of literature. Hence, the present study focused on antiresorptive therapy using a nondairy dietary supplement on the bone markers.

\section{Aims \& Objectives}

To investigate the influence of indigenously developed calcium rich plant based product on bone turnover markers of the selected menopausal women.

\section{Material \& Methods}

Based on the perceived and reported $(6,7,8)$ need for a suitable dietary calcium supplement the Indian Council of Medical Research database (1989) was surveyed to identify foods, which are rich in calcium $\&$ protein, low cost and easy availability. Based on the survey, fresh leaves of Agathi (Sesbania grandiflora), Sesame seeds (Sesamum indicum), Ragi (Eleusine coracana), Soybean (Glycine max) and Black gram dal (Vigna mungo) were selected for the study. The selected ingredients were combined in different ratios and the final product to be supplemented was chosen based on the organoleptic evaluation.(9) The developed product was analyzed for its Energy (Kcal), Carbohydrate (g), Protein (g), Fat (g) and Calcium (mg) content using David Pearson chemical analysis, DGHS manual, AOAC 19th edition 2012/920.87, AOAC 19th edition 2012/999.10. It was found that $100 \mathrm{~g}$ of the product contained 414 kilocalories, $19.3 \mathrm{~g}$ of protein, $58 \mathrm{~g}$ of carbohydrate, $11.7 \mathrm{~g}$ of fat, $701 \mathrm{mg}$ of calcium and $378 \mathrm{mg}$ of phosphorous. The ratio of calcium to phosphorous was found to be 1.85: 1 which is between the recommended ratio of 1:1 to $2: 1$.
[Plant based Indigenous...] | Gayathri G et al

\section{Participants, Randomization and Baseline} Assessment

The study was powered to detect a $5 \%$ change in bone turnover markers. Fifty volunteers were needed ( $80 \%$ power, $\alpha=0.05$ ) to complete the intervention, and 75 volunteers were recruited to account for possible dropouts (Figure 1). The participants were between the ages of 40 to 65 years from suburban areas of Chennai and the study was conducted from January 2017 to July 2017. The menopausal women were asked to mention their menopause age and whether it was natural or surgical. The perimenopausal women were asked to enlist the date of their last period. All women with $<1$ year to menopause were classified as perimenopausal and more than 1 year were classified as postmenopausal. The inclusion criteria were those found to be at risk of osteoporosis using the FRAX tool (computer driven tool) developed by WHO, consuming less than 1500mg of dietary calcium per day, not on any calcium supplementation, not a known case of cancer, liver and renal disease, hypo or hyperthyroidism, post hysterectomy state, no use of hormone replacement therapy within the previous three years. The subjects were randomly allocated by the investigator to control and experimental group using lottery method. This study was conducted according to the guidelines laid down in the Declaration of Helsinki and all procedures involving human subjects/patients were approved by the Institutional Ethics Committee of Sri Ramachandra Institute of Higher Education and Research (Deemed to be University), (Ref: IEC/15/FEB/114/02). Written informed consent was obtained from all participants. This trial was registered at the Clinical Trials Registry - India (Registry - India (Reg No: CTRI/2017/03/008272, Ref No: REF/2015/05/008903).

Baseline information's like demographic data which includes the age, social status, qualification, occupation, marital status, nature of work, co morbid conditions and family history of co morbid conditions, menstrual/gynaec history and physical activity (average time spent on walking) were obtained through interview schedule. Anthropometric data included assessment and interpretation of height, weight, BMI. Presence or absence of nocturnal bone pain was also documented as the nocturnal bone pain is one indicator of reducing bone mass. Dietary calcium 
intake was assessed using a validated quantitative food frequency questionnaire (7) and calcium intake was calculated manually and recorded by the investigator.

\section{Biospecimen Collection and Analyses of Bone Markers}

The biochemical data included assessment of bone turnover markers beta crosslaps (CTX) (to assess the bone resorption), total P1NP (to assess the bone formation) and serum calcium (to evaluate any incidence of toxicity as per the recommendation of institutional ethical committee). Fasting blood samples were drawn at each time point between 07.00 and 9.00 A.M from the subjects for the analysis of the markers with the help of a phlebotomist, using standard techniques. The collected samples were taken in tubes containing EDTA, centrifuged and then stored in polypropylene tubes at $4-8^{\circ} \mathrm{C}$ until analysis. Time points were baseline, after 3 and 6 months. Calcium analysis was carried out by spectrophotometry and betacrosslaps, P1NP by electrochemiluminescence, sandwich immunoassay. The tests were carried out with the help of a National Accreditation Board for Testing and Calibration Laboratories (NABL) accredited haematological lab.

\section{Amount of Calcium Supplementation}

The RDA 2010 for Indians recommends a calcium intake of $800 \mathrm{mg} /$ day for postmenopausal and 600 $\mathrm{mg} /$ day for perimenopausal women. Dietary intake of calcium was analysed in the same study area using dietary recalls, quantitative questionnaires and laboratory analysis of actual food samples. The result showed that the average intake of dietary calcium was $407.14 \pm 107.96 \mathrm{mg} /$ day (6), $425.30 \pm 101.71 \mathrm{mg}$ among males $(n=400)$ and $407.14 \pm 107.96 \mathrm{mg}$ among females $(n=400)$ (7). A quantitative assessment of dietary calcium intake was carried out by Sindhu latha (8) wherein food samples were collected from the subjects in polythene bags for three consecutive days including two weekdays and one weekend. After analysis it was found that, the mean calcium intake was $477.8 \pm 121.5 \mathrm{mg} /$ day among males and $410.2 \pm 112.8 \mathrm{mg} /$ day among females.

Based on the above studies, it is evident that the average intake of calcium among women is $\sim 400$ $\mathrm{mg} /$ day and the available calcium was $200 \mathrm{mg} /$ day considering the bioavailability as $50 \%(10,11,12,13)$. Reducing the average intake from the RDA and again considering $50 \%$ bioavailability, the amount of calcium to be supplemented for 6 months was determined as $1200 \mathrm{mg} /$ day and $800 \mathrm{mg} /$ day for postmenopausal and for perimenopausal subjects respectively.

\section{Supplementation}

The standardized product was made into ladoos (nutria balls) and supplemented by the investigator to the experimental group whereas the control group did not receive any supplement. It was distributed to the experimental group at their residence and instructed to be consumed as a midmorning and evening snack at the rate of 2 (120 g) and 4 (180 g) laddos per day for Peri and Postmenopausal subjects respectively. The calcium rich nutri balls were prepared on weekly basis, 14 ladoos for Perimenopausal subjects and 28 ladoos for Postmenopausal subjects and were packed into BOPP (Biaxially Oriented Polypropelyene) packaging covers to protect the nutritional properties of the food till final consumption and have sufficient barrier to moisture, gas and light. Instructions were also provided on proper storage and shelf life of the product.

Both the control group and study group of subjects were instructed to continue their regular habitual diet and regular physical activity during the entire period of study. In order to ensure the consistency of the calcium content in the distributed product the samples were analyzed randomly five times during the supplementation period. Compliance to the consumption of the supplementation was monitored through telephonic conversation every alternative day. The overall adherence level was calculated by the following formula.

Overall adherence

$=\frac{\text { Number of days supplement } \text { was consumed }}{\text { Number of days supplement was dispensed }} \times 100$

The anthropometric and the biochemical data were reassessed for both the groups after three (intermediate assessment) and six (final assessment) months of the supplementation period to analyze the effect of supplementation on the bone turnover markers. Dietary calcium intake was assessed by the quantitative questionnaire every two months of the supplementation period.

\section{Statistical Analysis}

The collected data were analysed with IBM.SPSS statistics software 23.0 Version. To describe about the data descriptive statistics frequency analysis were used for categorical variables and the mean \pm S.D were used for continuous variables. To find the significant difference between the bivariate samples for Independent groups the Unpaired sample t-test 
was used for normal data and the Mann-Whitney $U$ test was used for Skewed data. For repeated measures the Repeated measures of ANOVA with adjustment for multiple comparisons to control the type I error, the Bonferroni test was used for normal data and the Friedman test was used for Skewed data. To find the significance in categorical data ChiSquare test and Fisher's exact test was used. In all the above statistical tools the probability value $\leq 0.05$ was considered to be significant.

\section{Results}

A total of 75 subjects were screened out of which 60 subjects $(30$ perimenopausal and 30 postmenopausal subjects respectively) were found to be eligible for the study based on their history of menopause, the inclusion and exclusion criteria and based on their voluntary participation. [Figure 1] represents the participant selection process of the study. No adverse effects were observed.

Among postmenopausal subject's majority $53 \%$ of them experienced nocturnal bone pain and $46 \%$ did not experience. Body weight of the postmenopausal subjects in both the groups was higher than the perimenopausal subjects. [Table 1] shows the baseline characteristics of the subjects. The mean dietary calcium intake was found to meet $75 \%$ of the recommended daily allowance of perimenopausal subjects and $54 \%$ in postmenopausal subjects. There was no statistical difference observed between the baseline characteristics like weight, BMI, dietary calcium intake, serum calcium of the subjects both in post and perimenopausal groups.

During the period of supplementation there was no significant difference in the quantity of dietary calcium intake from the regular diet among the subjects in both the groups. Ninety-eight percent adherence level was observed among the subjects in the experimental groups.

After the intervention, it was found that there was a significant reduction in the presence of nocturnal bone pain among the experimental group of the perimenopausal subjects $(P=0.001)$ and postmenopausal subjects $(P=0.010)$. There was no change in the occurrence of pain among the control subjects [Figure 2] and [Figure 3].

The bone resorption marker (betacrosslaps/CTX) was found to be reducing from baseline to 3 and 6 months of supplementation in experimental groups. The decrease was found to be statistically significant $(P=0.008, \quad P=0.012)$ in perimenopausal and postmenopausal subjects respectively [Table 2]. Comparison between the control and experimental subjects also showed a significant $(P=0.024)$ reduction in postmenopausal women [Table 3$]$. The plant based dietary calcium supplementation proved to be significantly reducing the bone resorption marker especially in the postmenopausal subjects.

The bone formation marker (Total P1NP) did not show any significant change during the intervention from baseline to 3 and 6 months among the groups [Table 4]. It also did not show a change between the control and experimental group [Table 3].

\section{Discussion}

Evidence suggests that calcium intake is a modifiable risk factors for the maintenance of bone mass and skeletal integrity as well as for the reduction of osteoporotic risk. Use of functional foods to slow down the onset of osteoporosis has been receiving increased research attention.

On comparing the rate of reduction of the bone markers between the peri and postmenopausal groups, it was observed that the Beta crosslaps (CTX) levels have significantly $(P<0.05)$ reduced in postmenopausal group of subjects, than the perimenopausal group of subjects, which infers that the dietary calcium supplement has shown a marked reduction in those, where the bone resorption was higher.

This result also supports a similar finding by Kruger (14) wherein there was a significant decrease in CTX level $(P<0.001)$ s. observed in Chinese postmenopausal subjects following supplementation of two servings per day of high calcium milk (Total: $900 \mathrm{mg}$ calcium) for six weeks. A randomized controlled study done by Bonjour (2) for six weeks also reported a significant reduction in the bone resorption marker of community dwelling women with relatively lower risk of fracture, after the consumption of calcium fortified soft white cheese with adequate protein intake.

Nocturnal bone pain is a common symptom seen among menopausal women hence the presence of pain was also documented along with the other outcome parameters. It was found that few of the subjects had cessation of pain after the supplementation. Chi square analysis of the observations revealed a significant $(P<0.01, P<0.05)$ reduction in the pain related symptoms among the experimental group of the perimenopausal subjects and postmenopausal subjects. The reduction of the 
pain could have been because of the increased calcium intake from the supplement that helped in reducing the bone resorption. Various other components in the developed supplement like isoflavones, phytoestrogens formononetin, biochanin A, daidzein, and genistein could have also helped in relieving bone pain among the subjects.

The current study shows that consuming minimally processed food and attaining the recommended daily allowance from dietary sources has better biological effect. This adds further evidence to the theory that development of a range of new minimally processed nutritional supplements is necessary for reducing the risk of osteoporotic fracture. To our knowledge, this study improves on previous researches and practice, as it is the first to address a unique intervention strategy by supplementing low cost dietary calcium sources in the context of osteoporosis treatment and prevention. From this short-term intervention, daily consumption of calcium rich product made from indigenous low cost sources was efficient in reducing the bone resorption.

\section{Conclusion}

Use of functional foods to slow down the onset of osteoporosis has been receiving increased research attention. To our knowledge, this study improves upon on previous researches and practices, as it is the first to address a unique intervention strategy by supplementing low cost dietary calcium sources in the context of osteoporosis treatment and prevention.

\section{Recommendation}

Awareness and education has to be imparted among women on the available low cost sources and its benefits in bone health. These sources have to be incorporated in the daily diet for attaining the peak bone mass and preventing metabolic bone disorders in future.

\section{Limitation of the study}

The present study also has some limitations. Serum vitamin D, Phosphorus status of the subjects was not analyzed.

\section{Relevance of the study}

Achieving the daily calcium recommendation through locally available low cost calcium rich dietary sources is substantial for the attainment of a healthy bone mass

\section{Authors Contribution}

Both authors have contributed equally.

\section{Acknowledgement}

We would like to put on record our appreciation for the subjects for participating in this trial. We highly appreciate the support rendered by our Institution.

\section{References}

1. Lambert M, Hu L, Jeppesen P. A systematic review and meta-analysis of the effects of isoflavone formulations against estrogen-deficient bone resorption in peri- and postmenopausal women. The American Journal of Clinical Nutrition 2017;106(3): 801-811

2. Bonjour JP, Benoit V, Rousseau B, Souberbielle JC. Consumption of vitamin D-and calcium-fortified soft white cheese lowers the biochemical marker of bone resorption TRAP $5 \mathrm{~b}$ in postmenopausal women at moderate risk of osteoporosis fracture. J Nutr. 2012;142(4):698-703. doi: 10.3945/jn.111.153692. Epub 2012 Feb 22. PMID: 22357739.[PubMed].

3. Bolland MJ, Grey A, Avenell A, Gamble GD, Reid IR. Calcium supplements with or without vitamin $D$ and risk of cardiovascular events: reanalysis of the Women's Health Initiative limited access dataset and metaanalysis. BMJ. 2011 19;342:d2040. doi: 10.1136/bmj.d2040. PMID: 21505219; PMCID: PMC3079822.[PubMed].

4. Lee KJ, Kim KS, Kim HN, Seo JA, Song SW. Association between dietary calcium and phosphorus intakes, dietary calcium/phosphorus ratio and bone mass in the Korean population. Nutr J. 2014 13;13(1):114. doi: 10.1186/1475-2891-13-114. PMID: 25496564; PMCID: PMC4292818.[PubMed].

5. Aptel I, Cance-Rouzaud A, Grandjean H. Association between calcium ingested from drinking water and femoral bone density in elderly women: evidence from the EPIDOS cohort. J Bone Miner Res. 1999;14(5):82933. doi: 10.1359/jbmr.1999.14.5.829. PMID: 10320532.[PubMed].

6. Malathy S, Gayathri G, Hemamalini AJ. Developing and validating food frequency questionnaire to assess dietary intake of calcium in adults. International Journal of Food and Nutritional Science 2013; 2: 113- 115.

7. Gayathri $G$ and Hemamalini A J. Dietary Calcium Intake Among Adults. Indian Journal of Research 2017;6(1)

8. Sindhu latha A P., Gayathri $G$ and Hemamalini A J. Dietary Calcium Intake Among Adults-A Quantitative Assessment. International Journal of Recent Scientific Researc 2017;8(6), 17765-17767.

9. Gayathri G and Hemamalini A J. Development of an indigenous calcium rich food supplement. International Journal of Home Science 2017; 3(2): 80-84

10. Brian L. Intermediate Nutrition. 1st ed. california: Human Nutrition (FNDH 400) Flexbook; https://med.libretexts.org/Bookshelves/Nutrition/Book \%3A_Intermediate_Nutrition_(Lindshield), 2020 
11. Gibson RS, Bailey KB, Gibbs M, Ferguson EL. A review of phytate, iron, zinc, and calcium concentrations in plantbased complementary foods used in low-income countries and implications for bioavailability. Food Nutr Bull. 2010;31(2 Suppl): S134-46. doi: 10.1177/15648265100312S206. PMID: 20715598. [PubMed].

12. Weaver CM, Proulx WR, Heaney R. Choices for achieving adequate dietary calcium with a vegetarian diet. Am J Clin Nutr. 1999;70(3 Suppl):543S-548S. doi: 10.1093/ajcn/70.3.543s. PMID: 10479229.[PubMed].
13. Yang J, Punshon T, Guerinot ML, Hirschi KD. Plant calcium content: ready to remodel. Nutrients. 2012 Aug;4(8):1120-36. doi: 10.3390/nu4081120. Epub 2012 21. PMID: 23016135; PMCID: PMC3448090.[PubMed].

14. Kruger MC, Ha PC, Todd JM, Kuhn-Sherlock B, Schollum LM, Ma J, Qin G, Lau E. High-calcium, vitamin D fortified milk is effective in improving bone turnover markers and vitamin D status in healthy postmenopausal Chinese women. Eur J Clin Nutr. 2012;66(7):856-61. doi: 10.1038/ejcn.2012.54. Epub 2012 May 30. PMID: 22644348.[PubMed]

\section{Tables}

TABLE 1 BASELINE CHARECTERISTICS

\begin{tabular}{|c|c|c|c|c|c|c|c|c|c|c|}
\hline \multirow{4}{*}{$\begin{array}{l}\text { PARA } \\
\text { METERS }\end{array}$} & \multirow{2}{*}{\multicolumn{4}{|c|}{$\begin{array}{l}\text { PERIMENOPAUSAL } \\
\text { SUBJECTS }(\mathrm{N}=30)\end{array}$}} & $P$ - & \multirow{2}{*}{\multicolumn{4}{|c|}{$\begin{array}{l}\text { POST MENOPAUSAL } \\
\text { SUBJECTS }(\mathrm{N}=30)\end{array}$}} & \multirow{3}{*}{$\begin{array}{c}P \text { - } \\
\text { value }\end{array}$} \\
\hline & & & & & value & & & & & \\
\hline & \multicolumn{2}{|c|}{$\begin{array}{l}\text { CONTROL } \\
(n=15)\end{array}$} & \multicolumn{2}{|c|}{$\begin{array}{l}\text { EXPERIMENTAL } \\
\qquad(n=15)\end{array}$} & & \multicolumn{2}{|c|}{$\begin{array}{l}\text { CONTROL } \\
(n=15)\end{array}$} & \multicolumn{2}{|c|}{$\begin{array}{l}\text { EXPERIMENTA } \\
\qquad(n=15)\end{array}$} & \\
\hline & Mean & SD & Mean & SD & & Mean & SD & Mean & SD & \\
\hline WEIGHT (Kg) & 70.72 & 8.07 & 71.38 & 8.27 & $0.826^{\mathrm{NS}}$ & 79.4 & 8.25 & 77.56 & 5.37 & $0.474^{\mathrm{NS}}$ \\
\hline BMI $\left(\mathrm{Kg} / \mathrm{m}^{2}\right)$ & 27.79 & 2.17 & 28.06 & 2.49 & $0.749^{N S}$ & 30.2 & 2.52 & 30.2 & 2.4 & $0.996^{\mathrm{NS}}$ \\
\hline $\begin{array}{l}\text { DIETARY CALCIUM } \\
\text { INTAKE (mg/day) }\end{array}$ & 460.1 & 16.01 & 447.28 & 17.72 & $0.146^{N S}$ & 432 & 61.07 & 428.8 & 64.4 & $0.890^{\mathrm{NS}}$ \\
\hline SERUM CALCIUM (mg/dl) & 9.24 & 0.4 & 9.26 & 0.34 & $0.896^{\mathrm{NS}}$ & 9.39 & 0.32 & 9.39 & 0.4 & $0.968^{N S}$ \\
\hline
\end{tabular}

TABLE 2 BONE TURNOVER MARKERS IN EXPERIMENTAL GROUP

\begin{tabular}{|c|c|c|c|}
\hline \multirow{2}{*}{ BONE TURNOVER MARKERS } & \multirow{2}{*}{ PERIOD } & PERIMENOPAUSAL WOMEN & POSTMENOPAUSAL WOMEN \\
\hline & & (Mean \pm SD) & $($ Mean $\pm S D)$ \\
\hline \multirow[t]{4}{*}{ BETACROSSLAPS (CTX) ng/ml } & BASELINE $(n=15)$ & $0.32 \pm 0.13$ & $1.11 \pm 0.29$ \\
\hline & AFTER 3 MONTHS ( $n=15)$ & $0.29 \pm 0.11$ & $0.53 \pm 0.25$ \\
\hline & AFTER 6 MONTHS $(n=15)$ & $0.25 \pm 0.13$ & $0.53 \pm 0.25$ \\
\hline & $P$ value & $0.008 * *$ & $0.012 * *$ \\
\hline \multirow[t]{4}{*}{ TOTAL P1NP ng/ml } & BASELINE $(n=15)$ & $33.14 \pm 15.61$ & $37.62 \pm 17.20$ \\
\hline & AFTER 3 MONTHS $(n=14)$ & $33.39 \pm 14.70$ & $38.21 \pm 17.32$ \\
\hline & AFTER 6 MONTHS $(n=14)$ & $34.32 \pm 16.66$ & $39.59 \pm 17.86$ \\
\hline & $P$ value & $0.699^{\mathrm{NS}}$ & $0.326^{\mathrm{NS}}$ \\
\hline
\end{tabular}

Data is shown as Mean $\pm S D$. Repeated measures of ANOVA ${ }^{*} P<0.01, N S$ : Not significant, SD: Standard deviation

\section{TABLE 3 COMPARITIVE EFFECT OF DIETARY CALCIUM SUPPLEMENTATION ON BONE TURNOVER} MARKERS BETWEEN GROUPS

\begin{tabular}{|c|c|c|c|c|c|}
\hline \multirow[t]{5}{*}{ SUBJECTS } & \multirow[t]{5}{*}{ GROUP } & \multicolumn{2}{|c|}{ BETACROSSLAPS (CTX) } & \multicolumn{2}{|c|}{ TOTAL P1NP } \\
\hline & & \multicolumn{2}{|c|}{$\mathrm{ng} / \mathrm{ml}$} & \multicolumn{2}{|c|}{$\mathrm{ng} / \mathrm{mL}$} \\
\hline & & \multicolumn{2}{|c|}{$($ Mean $\pm S D)$} & \multicolumn{2}{|c|}{ (Mean $\pm S D)$} \\
\hline & & \multirow[t]{2}{*}{ BASELINE } & AFTER & \multirow[t]{2}{*}{ BASELINE } & AFTER \\
\hline & & & 6 MONTHS & & 6 MONTHS \\
\hline PERIMENOPAUSAL & CONTROL & $0.31 \pm 0.18(n=15)$ & $0.29 \pm 0.12(n=14)$ & $35.83 \pm 17.63(n=15)$ & $36.68 \pm 15.22(n=14)$ \\
\hline \multirow[t]{2}{*}{ WOMEN } & EXPERIMENTAL & $0.32 \pm 0.13(n=15)$ & $0.25 \pm 0.13(n=15)$ & $33.14 \pm 15.61(n=15)$ & $34.32 \pm 16.66(n=15)$ \\
\hline & $P$ value & $0.74^{\mathrm{NS}}$ & $0.92^{\mathrm{NS}}$ & $0.66^{\mathrm{NS}}$ & $0.689^{\mathrm{NS}}$ \\
\hline POSTMENOPAUSAL & CONTROL & $1.05 \pm 0.32(n=15)$ & $0.99 \pm 0.28(n=13)$ & $28.03 \pm 15.46(n=15)$ & $30.47 \pm 15.45(n=13)$ \\
\hline \multirow[t]{2}{*}{ WOMEN } & EXPERIMENTAL & $1.11 \pm 0.29(n=15)$ & $0.53 \pm 0.25(n=15)$ & $37.62 \pm 17.20(n=15)$ & $39.59 \pm 17.86(n=15)$ \\
\hline & $P$ value & $0.23^{\mathrm{NS}}$ & $0.024 * *$ & $0.11^{\mathrm{NS}}$ & $0.146^{\mathrm{NS}}$ \\
\hline
\end{tabular}

Data is shown as Mean $\pm S D$. Paired t test in comparison to respective baselines. Comparison between the groups at 6 months with student unpaired test ${ }^{* *} P<0.01$, NS: Not significant, SD: Standard deviation 


\section{TABLE 4 BONE TURNOVER MARKERS IN CONTROL GROUP}

\begin{tabular}{|c|c|c|c|}
\hline BONE TURNOVER & PERIOD & PERIMENOPAUSAL & POSTMENOPAUSAL \\
\hline \multirow[t]{2}{*}{ MARKERS } & & WOMEN & WOMEN \\
\hline & & (Mean $\pm S D)$ & (Mean $\pm S D)$ \\
\hline BETACROSSLAPS (CTX) & BASELINE $(n=15)$ & $0.31 \pm 0.18$ & $1.05 \pm 0.32$ \\
\hline \multirow[t]{3}{*}{$\mathrm{ng} / \mathrm{ml}$} & AFTER 3 MONTHS $(n=15)$ & $0.30 \pm 0.13$ & $0.91 \pm 0.24$ \\
\hline & AFTER 6 MONTHS $(n=15)$ & $0.29 \pm 0.12$ & $0.99 \pm 0.28$ \\
\hline & $P$ value & $0.249^{N S}$ & $0.307^{\mathrm{NS}}$ \\
\hline TOTAL P1NP & BASELINE $(n=15)$ & $35.83 \pm 17.63$ & $28.03 \pm 15.46$ \\
\hline \multirow[t]{3}{*}{$\mathrm{ng} / \mathrm{ml}$} & AFTER 3 MONTHS $(n=14)$ & $36.58 \pm 16.24$ & $29.75 \pm 15.61$ \\
\hline & AFTER 6 MONTHS $(n=14)$ & $36.68 \pm 15.22$ & $30.47 \pm 15.45$ \\
\hline & $P$ value & $0.345^{\mathrm{NS}}$ & $0.061^{\mathrm{NS}}$ \\
\hline
\end{tabular}

\section{Figures}

FIGURE 1 CONSORT DIAGRAM - PARTICIPANT SELECTION PROCESS

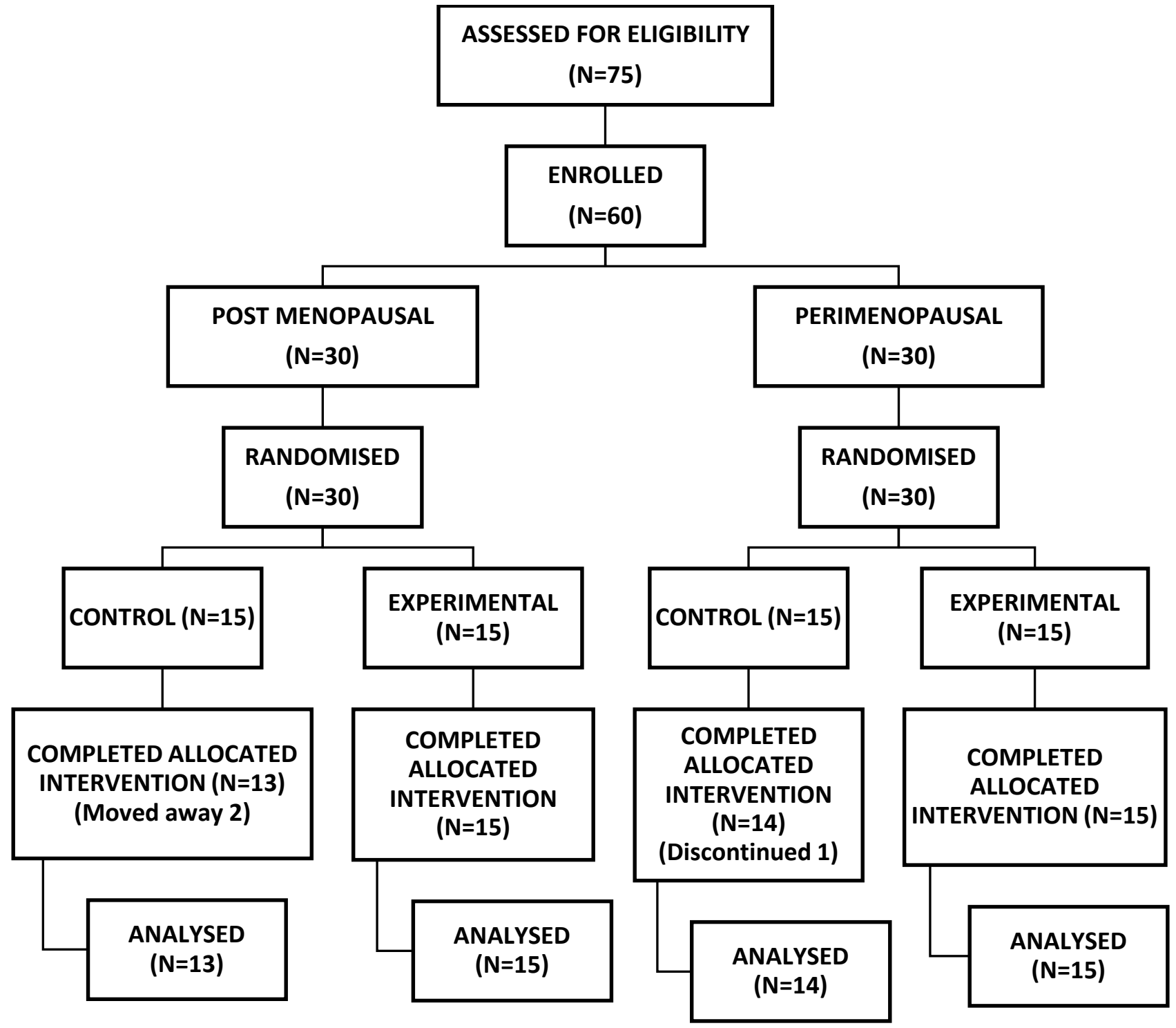


FIGURE 2 EFFECT OF DIETARY CALCIUM SUPPLEMENTATION ON NOCTURNAL BONE PAIN AMONG POST MENOPAUSAL SUBJECTS

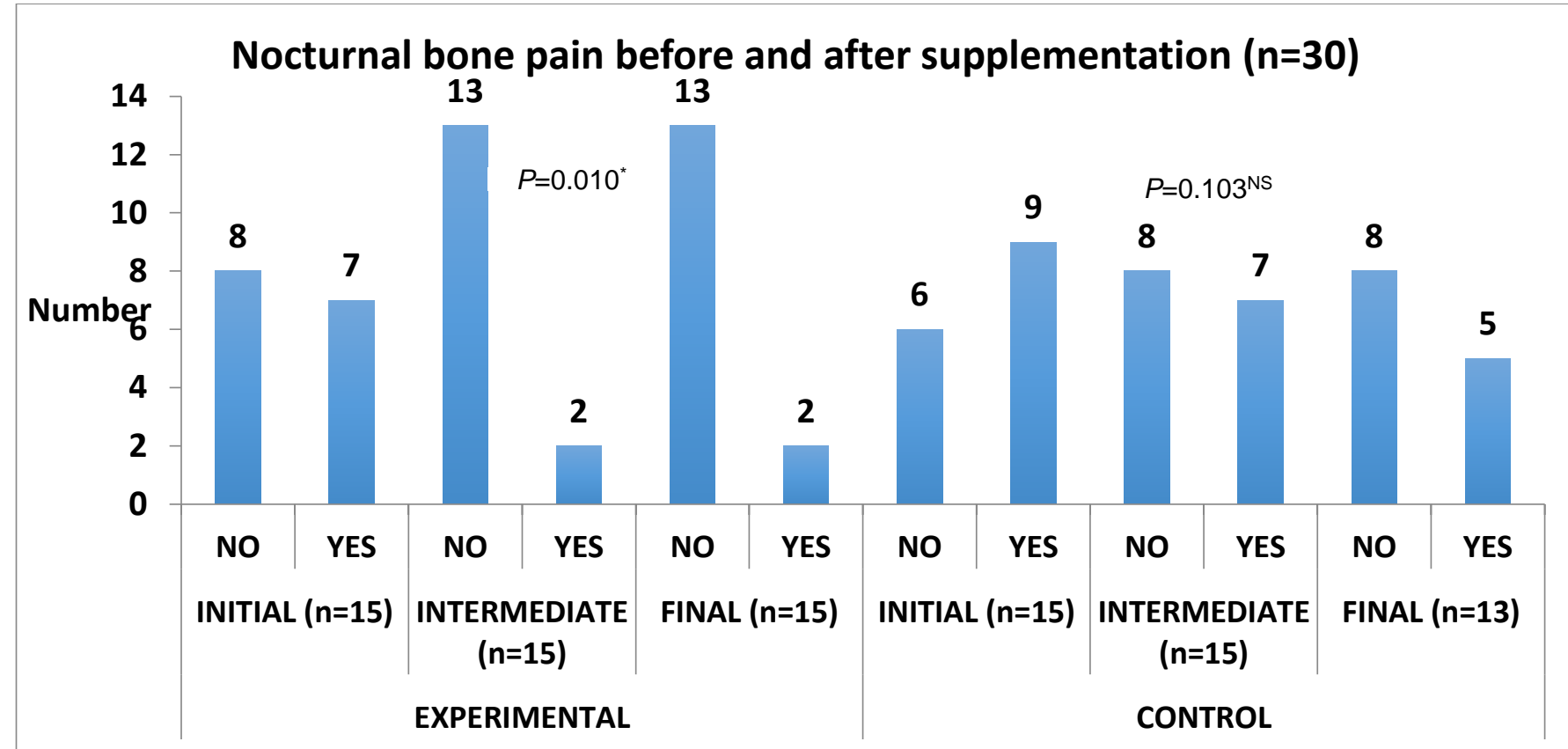

Legend: Data is shown as frequency. Chi-Square test and Fisher's exact test in comparison among the groups at baseline, 3 \& 6 months **P<0.01, *P<0.05 NS: Not significant

FIGURE 3 EFFECT OF DIETARY CALCIUM SUPPLEMENTATION ON NOCTURNAL BONE PAIN AMONG PERI MENOPAUSAL SUBJECTS

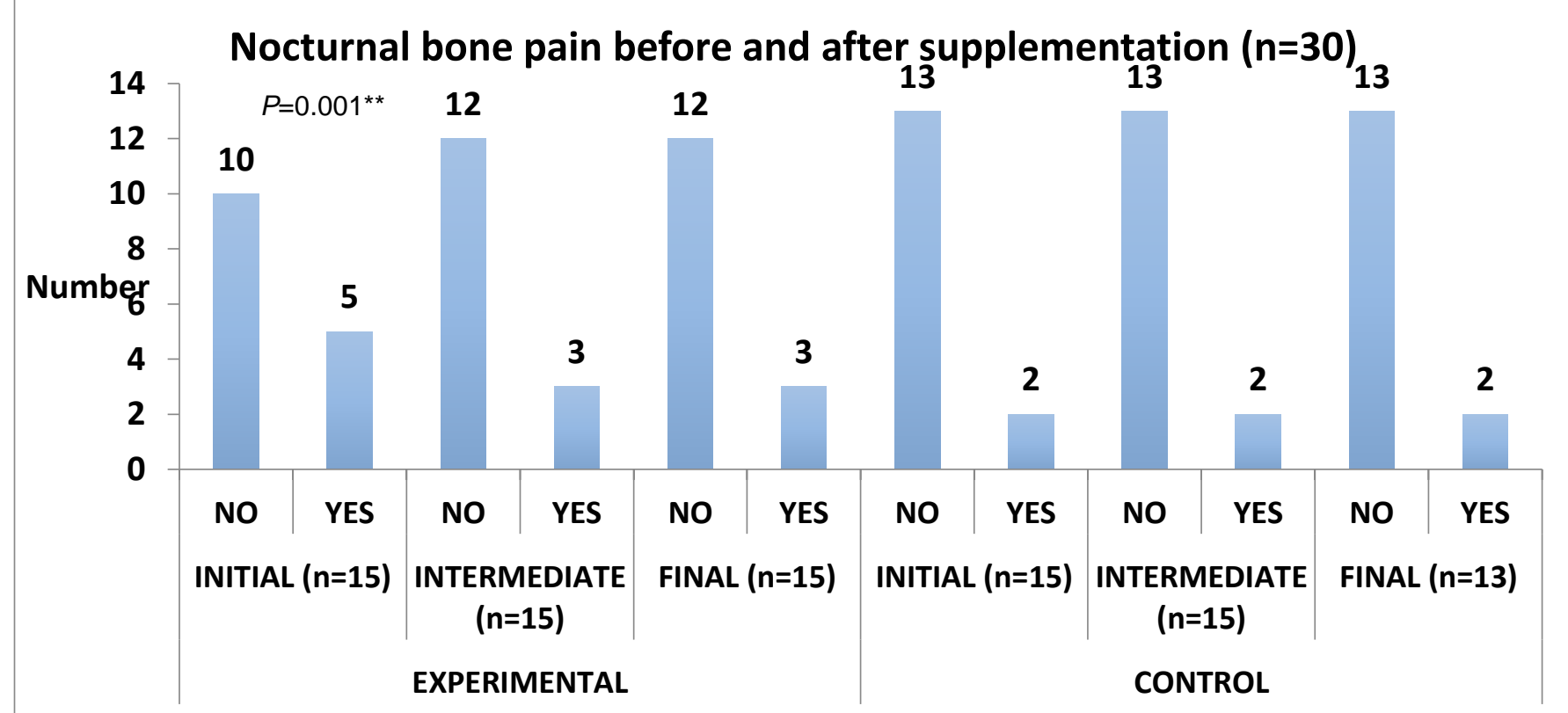

Legend: Data is shown as frequency. Chi-Square test and Fisher's exact test in comparison among the groups at baseline, 3 \& 6 months ${ }^{* *} P<0.01,{ }^{*} P<0.05$ NS: Not significant. Statistical analysis was not carried out since there were no difference seen in control group. 